\title{
Homofobia na Escola: Relatos de Universitários sobre as Piores Experiências
}

\author{
Paloma Pegolo de Albuquerque ${ }^{1}$ \\ Centro de Educação e Ciências Humanas da Universidade Federal de São Carlos, \\ São Carlos, SP, Brasil \\ Lúcia Cavalcanti de Albuquerque Williams \\ Departamento de Psicologia da Universidade Federal de São Carlos, São Carlos, SP, Brasil
}

\begin{abstract}
Resumo
A homofobia pode estar presente nas escolas de diversas formas, envolvendo múltiplos agentes escolares e favorecendo o desenvolvimento de diferentes sintomas psicológicos e psiquiátricos por parte das vítimas. A presente pesquisa teve o objetivo de descrever os relatos retrospectivos de estudantes universitários sobre as suas piores experiências escolares motivadas por homofobia, apontando a duração das mesmas, os principais agressores envolvidos e os sintomas advindos dessas experiências. Entre os 638 participantes que responderam à "Escala sobre Experiências Escolares Traumáticas em Estudantes - Revisada" de um estudo mais amplo sobre vitimização escolar, 21 (3,3\%) descreveram componentes homofóbicos na pior experiência. Os relatos descrevem principalmente vitimização verbal e também situações de isolamento social, sendo que para 14 desses estudantes a experiência durou "anos". Em relação às consequências da homofobia, 19 participantes apontaram que se "incomodaram muito com a experiência", sendo descritos sintomas clinicamente significativos, tais como de depressão e de Transtorno de Estresse Pós-Traumático. Aponta-se a necessidade de novas pesquisas e são discutidas potenciais intervenções na escola para combater a homofobia.
\end{abstract}

Palavras-chave: Homofobia na escola, bullying homofóbico, sintomas de homofobia na escola.

\section{Reports from University students on their Worst School Experiences on Homophobia}

\begin{abstract}
Homophobia may be present at schools in several ways, involving multiple school agents, and favoring the development of many psychological and psychiatric symptoms by victims. This study aimed to describe university students retrospective reports on their worst school experiences motivated by homophobia, identifying their duration, main perpetrators involved, and symptoms resulting from these experiences. Among the 638 participants who answered the "Student Alienation and Trauma Survey - R" for a larger Brazilian study on school victimization, 21 (3.3\%) reported homophobic components in their worst experience. The reports describe mainly verbal victimization and also social isolation situations, and for 14 students the experience lasted for "years". In terms of consequences from homophobia, 19 participants indicated that they were "much bothered from the experience", describing clinically
\end{abstract}

Endereço para correspondência: Rua Guatemala, 166, Vila Brasília, São Carlos, SP, Brasil 13566-720. Fones: (16) 3306-9405, 98221-4571. E-mail: palomanier@yahoo.com.br

Agência de financiamento: Fundação de Amparo a Pesquisa do Estado de São Paulo (FAPESP) - Processo 2010/01379-5. 
significant symptoms, such as from depression and Post-Traumatic Stress Disorder. The need for further research is pointed out, and potential interventions in school to combat homophobia are discussed.

Keywords: School homophobia, homofobic bullying, school homophobia symptoms.

\section{Homofobia en la Escuela: Los Informes de los Estudiantes Universitarios acerca de las Peores Experiencias}

\section{Resumen}

La homofobia puede estar presente en las escuelas de varias maneras, con la participación de múltiples agentes de la escuela, y favoreciendo el desarrollo de varios síntomas psicológicos y psiquiátricos en las víctimas. Este estudio tuvo como objetivo describir los informes retrospectivos de los estudiantes universitarios acerca de sus peores experiencias escolares motivados por la homofobia, señalando los principales perpetradores involucrados y los síntomas derivados de estas experiencias. Entre los 638 participantes que respondieron a la "Escala de experiencias traumáticas en la Escuela Los estudiantes - Revisado" de un estudio más amplio de la victimización escolar, 21 (3.3\%) informaron componentes homofóbicos en la peor experiencia. Los informes describen victimización principalmente verbal y también situaciones de aislamiento social, y para 14 de estos estudiantes experiencia duraron "años". En cuanto a las consecuencias de la homofobia, 19 participantes indicaron que "se molestó mucho con la experiencia" y describió clínicamente síntomas significativos, tales como el trastorno de la depresión y el trastorno de estrés postraumático. Señaló la necesidad de más investigación y se discuten las posibles intervenciones en las escuelas para combatir la homofobia.

Palabras clave: Homofobia en la escuela, bullying homofóbico, los síntomas de la homofobia en la escuela.

A escola enfrenta diversos desafios para lidar com a diversidade, inclusive com a questão da homossexualidade, sendo que a hostilidade para com os homossexuais é denominada de homofobia (Borrillo, 2009). Para Espelage, Basile e Hamburger (2012) a homofobia é definida como atitudes e comportamentos negativos contra pessoas que se identificam como ou são percebidos como lésbicas, gays, bissexuais ou transgêneros (LGBT). Alguns pesquisadores afirmam que jovens que estão se questionando acerca da própria sexualidade também podem ser alvo desse tipo de violência (Taylor, Peter, \& Paquin, 2011; Williams, Connolly, Pepler, \& Craig, 2003).

A homofobia pode estar presente nas escolas de diferentes formas, até mesmo como violência simbólica, a qual pode ser percebida, por exemplo, nos materiais didáticos, nas concepções curriculares e nas relações pedagógicas normatizadoras (Prado \& Junqueira, 2011). Para
Russell (2011) isso acontece porque a escola, assim como a sociedade, caracteriza-se por normas rígidas de gênero e sexualidade, como expectativas a respeito da masculinidade, feminilidade e heterossexualidade.

De acordo com Bekaert (2010), quando a homofobia na escola é traduzida em palavras e ações, há risco de tornar-se bullying homofóbico. A definição de bullying refere-se a ações físicas e sociais negativas que são cometidas intencionalmente, repetidamente, ao longo do tempo por uma ou mais pessoas contra um indivíduo que não pode se defender facilmente (Olweus, 1991). Geralmente as vítimas de bullying apresentam uma característica diferenciada que as tornam alvos fáceis da violência, podendo ser a orientação sexual e/ou identidade de gênero. O bullying pode envolver componentes físicos (agressões), verbais (como xingamentos, provocações), relacionais (tais como espalhar rumores) e sexuais (assédio). Alguns exemplos 
de agressões homofóbicas na escola são provocações, ameaças, assédio e agressões (Poteat \& Espelage, 2005).

\section{Pesquisas sobre Homofobia na Escola}

Um corpo bem estabelecido de pesquisas documenta a violência, assédio e falta de segurança na escola para estudantes LGBT (Russell, 2011), sendo que, frequentemente, esses estudantes experienciam situações de bullying (Berlan, Corliss, Field, Goodman, \& Austin, 2010; Birkett, Espelage, \& Koenig, 2009; Espelage et al., 2012; Williams et al., 2003).

Berlan et al. (2010) realizaram uma pesquisa com 7.559 jovens norte americanos de 14 a 22 anos para examinar o relacionamento entre orientação sexual e vitimização por bullying e encontraram que, comparados aos heterossexuais, os jovens homossexuais tinham maior probabilidade de relatar ter sofrido bullying. No estudo de Birkett et al. (2009) com 7.376 estudantes norte americanos, com o objetivo de examinar como os fatores contextuais da escola, tais como a vitimização homofóbica e o clima escolar negativo, impactam o bem estar de jovens lésbicas, gays ou bissexuais (LGB) no Ensino Médio, os autores encontraram que os estudantes LGB tinham maior probabilidade de relatarem altos níveis de bullying homofóbico e impactos negativos, como uso de drogas, depressão e ideias suicidas. Rivers (2004) realizou um estudo retrospectivo em que pesquisou a vivência de bullying homofóbico numa amostra de 119 jovens ingleses e obteve como resultado principal que todos relataram ter sido vitimizados, sendo que a idade média para início do bullying foi 10,5 anos e o tempo médio de duração do evento foi cinco anos.

O Instituto Nacional de Estudos e Pesquisas Educacionais Anísio Teixeira (INEP, 2010) realizou um estudo sobre diversidade na escola em 500 escolas públicas de todo o Brasil, contando com uma amostra final de questionários respondidos por 501 diretores, 1.005 professores, 1.004 funcionários, 15.087 alunos e 1.002 pais/mães de alunos. A análise dos resultados da pesquisa revelou que os seus diversos públicos-alvo (diretores, professores, funcionários, alunos e pais / mães) apresentam atitudes, crenças e valores que indicam que o preconceito é uma realidade nas escolas públicas brasileiras nas sete áreas temáticas de discriminação pesquisadas (étnico-racial, deficiência, gênero, geracional, socioeconômica, territorial e identidade de gênero), sendo que $72 \%$ da amostra apresentou atitude discriminatória contra homossexuais. Dentre os resultados, constatou-se que $17 \%$ relatou ter conhecimento de que alunos homossexuais foram humilhados, agredidos ou acusados injustamente pela orientação sexual e $40 \%$ dos diretores presenciaram ou souberam de situações de alunos serem humilhados por serem homossexuais.

Venturi e Bokany (2011) realizaram um levantamento chamado "Diversidade Sexual e Homofobia no Brasil", no qual 2014 pessoas adultas de idades a partir de 16 anos, de 150 municípios (pequenos, médios e grandes) nas cinco regiões brasileiras responderem a um questionário. Os pesquisadores perceberam incoerências no discurso dos entrevistados, como por exemplo, perguntados sobre se existia preconceito contra homossexuais no Brasil, $92 \%$ afirmaram que sim, mas apenas $26 \%$ afirmaram ser preconceituoso contra gays e $27 \%$ contra lésbicas. Desses, 54\% indicou apresentar preconceito leve; $39 \%$ preconceito mediano e $6 \%$ forte preconceito, sendo que apenas $1 \%$ relatou não apresentar qualquer preconceito de natureza homofóbica. Comportamentos homofóbicos foram aferidos em uma a cada cinco mulheres e um a cada três homens, sendo que as taxas eram maiores com a diminuição da renda e o aumento da idade (embora muito altas no extremo mais jovem, sobretudo entre adolescentes de 16 e 17 anos). Por exemplo, 7\% afirmou que expulsaria o(a) filho(a) de casa se soubesse que esse(a) era gay ou lésbica. Esses pesquisadores também entrevistaram 413 homossexuais e bissexuais em 18 municípios das cinco regiões brasileiras e obtiveram resultados que apontam altos índices de preconceito: uma grande parte afirmou que se sentiu discriminado devido à orientação sexual e o agente discriminador em $27 \%$ dos casos eram colegas da escola e para 7\% eram professores; $13 \%$ relatou discriminação ao entrar em uma nova escola. As formas de violência homofóbica mais frequentes foram: $52 \%$ já sofrera violência; 
$42 \%$ foram tratados com ironia ou gozação; e $10 \%$ foi ameaçado ou aterrorizado (Venturi \& Bokany, 2011).

\section{Associação entre Bullying Homofóbico e Sintomas Psicológicos e Psiquiátricos}

Dentre os efeitos do bullying homofóbico listados na literatura destacam-se: depressão (Birkett et al., 2009; Kosciw, Greytak, Bartkiewicz, Boesen, \& Palmer, 2012; Russell, 2011; Russell, Ryan, Toomey, Diaz, \& Sanchez, 2011; Taylor et al., 2011); Transtorno de Estresse Pós-traumático (TEPT; Rivers, 2004); ideação suicida e/ou tentativa de suicídio (Birkett et al., 2009; Bontempo \& D'Augelli, 2002; Faulkner \& Cranston, 1998; Hershberger \& D'Augelli, 1995; Rivers, 2001, 2004; Russell, 2011; Russell et al., 2011); alcoolismo e abuso de substância (Birkett et al., 2009; Bontempo \& D'Augelli, 2002; Faulkner \& Cranston, 1998; Rivers, 2004; Russell, 2011); transtornos alimentares (Rivers, 2004); práticas sexuais não seguras e/ ou evitação de estratégias de proteção, no que se refere a sexo, tais como uso de preservativos (Bontempo \& D'Augelli, 2002; Faulkner \& Cranston, 1998; Rivers, 2004); desempenho escolar empobrecido (Prado \& Junqueira, 2011); faltas à escola (Bontempo \& D'Augelli, 2002; Faulkner \& Cranston, 1998; Kosciw et al., 2012; Taylor et al., 2011); e comportamento violento (Faulkner \& Cranston, 1998; Rivers, 2004).

Além disso, esses indivíduos vitimizados podem apresentar dificuldades em estabelecer e manter relacionamentos íntimos (Rivers, 2004). De acordo com Williams et al. (2003) a integração num grupo de pares pode ser problemática para as minorias sexuais, isso porque tais minorias têm que lidar com incertezas de identidade sexual e a hostilidade tanto por pares quanto por parceiros românticos, o que pode aumentar as dificuldades em saúde mental. Isso é acentuado pelo fato de a adolescência ser um período de desenvolvimento da identidade e questionamento da própria sexualidade, sendo que cerca de $10 \%$ dos jovens experienciam alguma incerteza acerca da orientação sexual (Williams et al., 2003). Podem ocorrer, ainda, sentimentos de desvalorização, conhecidos como homofobia internali- zada (Rivers, 2004) e culpa após a vitimização (Bontempo \& D’Augelli, 2002).

\section{Dados de Pesquisa Acerca do Impacto da Homofobia na Saúde Mental dos Estudantes}

Para examinar a ligação entre vitimização escolar e efeitos na saúde mental de jovens LGB, Bontempo e D'Augelli (2002) coletaram dados com 1995 jovens nos Estados Unidos, sendo 315 homossexuais. Os resultados mostraram que os estudantes LGB, comparados aos heterossexuais, apresentaram níveis mais altos de vitimização escolar, sendo que esses estiveram associados a altos níveis de uso de substâncias, ideação suicida, e comportamentos sexuais de risco. Jovens LGB que reportaram baixos índices de vitimização apresentaram níveis similares aos dos heterossexuais no que se refere às variáveis citadas. Isso aponta que as diferenças nos riscos para a saúde mental dos jovens LGB podem ser mediadas pela vitimização escolar. Os autores ainda ressaltam ser possível que pesquisas como essas não incluam os jovens mais afetados pelo bullying homofóbico, pois esses encontram-se fora da escola e isolados.

Após mais de uma década de pesquisas examinando os indicadores negativos do clima escolar para os jovens LGBT, Kosciw et al. (2012) apresentaram dados obtidos com 8.584 estudantes entre 13 e 20 anos de 50 estados dos Estados Unidos. Os resultados apontam que as escolas são ambientes hostis para os jovens homossexuais e $63,5 \%$ desses jovens afirmaram que se sentiam inseguros devido à orientação sexual; $81,9 \%$ foram verbalmente assediados, por exemplo, xingados ou ameaçados; $84,9 \%$ ouviam frequentemente na escola a palavra "gay" utilizada de forma pejorativa; $71,3 \%$ ouviam outros tipos de comentários homofóbicos de colegas e $91,4 \%$ reportaram ter se sentido perturbados com essa linguagem. No que se refere à vitimização física (por exemplo, ser empurrado); 38,3\% relataram que sofreram tal vitimização no ano anterior à pesquisa; e 55,2\% também relataram vitimização por cyberbullying (por meio de mensagens de texto ou postagens em sites de relacionamento). Acerca do desempenho escolar, 31,8\% 
apontaram ter perdido ao menos um dia de aula no último mês devido a se sentir desconfortável ou inseguro com os assédios. Estudantes que experienciaram altos níveis de vitimização apresentaram três vezes mais chance de ter faltado à escola do que os que apresentaram baixos níveis (57,9\% versus $19,6 \%)$. Os estudantes mais frequentemente assediados apresentavam notas inferiores às dos menos assediados e os mais vitimizados reportaram duas vezes mais probabilidade de relatar que não tinham planos acadêmicos para o futuro, como entrar em uma universidade, do que os que eram menos vitimizados (10,7\% versus $5,1 \%)$. Sobre os efeitos psicológicos do bullying homofóbico, os estudantes que apresentaram altos índices de vitimização em decorrência de sua orientação sexual tiveram níveis de depressão mais altos e baixos níveis de autoestima comparados a estudantes que reportaram níveis baixos de vitimização.

Foram também realizadas pesquisas retrospectivas relacionadas à vitimização homofóbica. Rivers (2004) conduziu um estudo com o objetivo de investigar a associação entre experiências de uma amostra de 119 participantes adultos identificados como LGBT do Reino Unido que reportaram bullying prolongado na escola devido à orientação sexual e impacto a longo prazo sobre suas vidas, focando especialmente em sintomas de estresse pós-traumático e seu relacionamento com outras variáveis, como comportamento sexual, homofobia internalizada, afeto negativo e ideação suicida. Os participantes responderam a vários questionários e alguns participaram de entrevistas. Os resultados indicaram que estresse pós-traumático foi um problema para $17 \%$, sendo que esses obtiveram altos escores também para depressão. Aproximadamente $26 \%$ indicaram que tiveram ou continuaram a ter problemas regulares de lembranças do bullying, sendo que a maioria reportou memórias intrusivas dos eventos, apresentando sofrimento diante de situações que os lembravam do evento; $4 \%$ apresentaram pesadelos relacionados ao evento e $9 \%$ relataram "flashbacks" relacionados. Toomey, Ryan, Diaz, Card e Russel (2010) fizeram uma pesquisa com 245 jovens LGBT (21 a 25 anos), investigando a relação entre orientação sexual, vitimização escolar por motivo LGBT percebida ou real na adolescência e seus impactos nos níveis de satisfação de vida e depressão na adultez. Como os níveis de vitimização escolar estiveram positivamente correlacionados a altos índices de depressão e baixos níveis de satisfação na vida adulta, os autores concluíram que a vitimização homofóbica continuava presente na vida adulta desses jovens, afetando a sua qualidade de vida.

Russell et al., (2011) examinaram a associação entre relatos de vitimização escolar LGBT, saúde psicossocial e comportamento de risco na adultez (depressão, ideação suicida, satisfação na vida, autoestima, integração social, tentativas de suicídio, depressão, adição ao álcool e uso de substâncias, doenças sexualmente transmissíveis [DSTs] e risco para vírus da imunodeficiência adquirida [HIV]) para 245 jovens LGBT adultos dos Estados Unidos, com idade média de 22,8 anos, que responderam a um instrumento retrospectivo. Os resultados principais apontam que a vitimização escolar esteve associada a risco aumentado para problemas de saúde mental, elevados níveis de depressão e comportamento suicida entre homens.

\section{Escolas como Ambientes Homofóbicos}

Algumas pesquisas apontam que muitos estudantes LGBT não se sentem seguros na escola e não podem contar com professores para auxiliá-los em situações de bullying homofóbico, sendo que educadores frequentemente não reportam situações de bullying homofóbico (Rivers, 2001) e podem até vitimizar os jovens (Birkett et al., 2009). O estudo de Kosciw et al. (2012) apontou que $35,2 \%$ dos participantes relataram que a equipe escolar nunca intervinha quando comentários homofóbicos eram feitos por estudantes; $56,9 \%$ ouviram comentários homofóbicos de professores ou equipe escolar e $56,9 \%$ dos estudantes também reportaram escutar comentários negativos sobre sua expressão de gênero; $60,4 \%$ dos estudantes que foram vitimizados na escola não reportaram o ocorrido para funcionários da escola, por achar que pouco ou nada seria feito ou a situação ficaria pior se o fizessem; e $36,7 \%$ 
dos estudantes que afirmaram ter relatado à equipe escolar informaram que nada foi feito em resposta.

Esses autores apontaram também que os estudantes que percebiam a escola como tendo um currículo inclusivo ouviam menos comentários homofóbicos e menos da metade $(43,4 \%)$ se sentia inseguro devido a sua orientação sexual, comparados a $67,5 \%$ dos outros estudantes LGBT que não consideram sua escola como tendo um currículo inclusivo; apenas $17,7 \%$ dos estudantes de escolas com currículo inclusivo haviam faltado à escola no mês anterior à pesquisa comparados a $34,8 \%$ de alunos de escolas sem currículo inclusivo. Adicionalmente, os primeiros tinham maior probabilidade de reportar que os colegas de classe aceitavam pessoas LGBT do que outros estudantes $(66,7 \%$ vs. $33,2 \%)$ e também se sentiam mais conectados à escola do que os outros estudantes.

\section{Objetivos}

O presente estudo buscou descrever os relatos retrospectivos de estudantes universitários sobre suas piores experiências escolares motivadas por homofobia, apontando a duração das mesmas, os principais agressores envolvidos e os sintomas advindos dessas experiências.

\section{Método}

\section{Participantes e Local}

Esse estudo utilizou um banco de dados de um estudo mais amplo, do qual participaram 691 estudantes de uma universidade pública do interior de São Paulo que responderam à "Escala sobre Experiências Escolares Traumáticas em Estudantes - Revisada (ExpT-R)" descrita na sessão "Instrumento" em seguida. Desse total, 638 participantes descreveram a sua pior experiência escolar no questionário. Foram selecionados participantes que descreveram vitimização escolar homofóbica como a pior experiência escolar, sendo tal número igual a 21 participantes ou $3,3 \%$.

A média de idade desses participantes foi de 21,3 anos; sendo 14 do sexo masculino e sete do feminino. Em relação à etnia, 16 declararam-se brancos, dois negros, dois pardos e um asiático. No que se refere à renda, comparados à maioria da população brasileira, a maioria, 12, declarou que sua renda era "Ligeiramente melhor do que a maioria", seis "Semelhante aos outros lares", dois "Muito melhor do que a maioria" e um "Ligeiramente pior do que a maioria". Sobre a formação acadêmica do membro que contribuía com maior renda familiar, sete declararam que essa pessoa "Concluiu Curso Superior", seis informaram que o membro "Concluiu o Ensino Médio e não ingressou em Curso Superior", três disseram que ele(a) "Não concluiu o Ensino Fundamental", três afirmaram que tal familiar "Iniciou o Ensino Médio, mas não concluiu" e dois afirmaram que ele(a) "Ingressou em Curso Superior, mas não se formou". Esses estudantes eram pertencentes às áreas: Biológicas (quatro participantes); Exatas (sete) e Humanas (10); e a maioria deles, 15 , estava nos dois primeiros anos do curso.

\section{Instrumento}

Foi utilizada uma versão traduzida e adaptada para o Brasil do instrumento retrospectivo Student Alienation and Trauma Survey- $R$, de Hyman e Snook (2002), denominado em português de "Escala sobre Experiências Escolares Traumáticas em Estudantes - Revisada (ExpT-R) (Albuquerque \& Williams, 2014)". O instrumento tem o objetivo de avaliar experiências de vitimização escolar e sintomas traumáticos decorrentes, especialmente de TEPT, além de possuir questões iniciais sobre os dados demográficos (idade, etnia, renda familiar e sexo). A primeira parte do instrumento possui itens sobre 58 experiências aversivas no contexto escolar e o autor da experiência. Ainda nesta primeira parte, o participante é solicitado a dar mais detalhes acerca de sua pior experiência escolar; devendo identificar o(s) envolvido(s) nesta experiência, quantos anos tinha quando a experiência ocorreu, qual foi a duração, qual série cursava na época, e como se sentiu após a experiência, sendo solicitado ao participante que descreva essa experiência com detalhes. A segunda parte do instrumento é constituída por uma lista de 
105 sintomas comuns após situações traumáticas, como TEPT; e todas as respostas devem ser dadas tendo como referência à pior experiência descrita na primeira parte do instrumento.

\section{Procedimento}

Antes de iniciar a coleta de dados, o projeto de pesquisa foi encaminhado para o Comitê de Ética em Pesquisa em Seres Humanos da Universidade e obteve aprovação. A aplicação do instrumento foi executada coletivamente em salas de aula da universidade, em horário de aula. Os participantes receberam informações sobre a coleta de dados, que envolvia questões sobre episódios negativos de sua vida e que sua participação poderia gerar algum tipo de desconforto ou estresse ao participante ao lembrar-se disso. Em seguida, eles preencheram Termos de Consentimento Livre e Esclarecido e, posteriormente, recebiam uma cópia do ExpT com numeração para manter em sigilo a identidade dos estudantes e eram dadas instruções detalhadas de como responder ao instrumento. Vale apontar que a primeira autora se colocava à disposição para conversar com os participantes que apresentassem necessidade após o preenchimento dos questionários, tendo realizado três encaminhamentos para serviços de atendimento psicológico.

\section{Resultados e Discussão}

\section{Piores Experiências Escolares Homofóbicas}

Foram descritos principalmente incidentes de vitimização verbal (comentários inadequados sobre a sexualidade dos estudantes, insultos, gozações, tentativas de ridicularizá-los, espalhamento de rumores, recebimento de apelidos indesejados) e também situações de isolamento social por parte dos colegas. Nesse sentido, a literatura aponta o quanto a vitimização verbal é frequente entre a população LGBT. Por exemplo, Venturi e Bokany (2011) apontaram que $42 \%$ dos indivíduos pesquisados por ele afirmaram ter sido tratados com ironia ou gozação e Kosciw et al. (2012) observaram que 81,9\% dos participantes respondentes do seu estudo foram verbalmente assediados, sendo, por exemplo, xingados ou ameaçados e $71,3 \%$ ouviram outros tipos de comentários homofóbicos de colegas. Na presente pesquisa a vitimização verbal também foi a mais citada, comum na forma de comentários maldosos, como demonstraram os relatos seguintes: "A maioria dos alunos faziam [sic] comentários desagradáveis a mim, sobre a minha opção sexual e sobre as roupas que eu usava na época" (Participante 476), e,

Era gordinho, meio nerd e meio afeminado. Essas três características fazem com que eu jamais esqueça da minha infância e tampouco tenha saudade dela. Recebia muitos apelidos; eu tinha medo de passar na rua desses alunos que me perseguiam e, por vezes, andava o dobro do caminho só pra não ouvir insultos ao andar pelo bairro. (Participante 455)

Esse relato deixa claro o impacto que a vitimização pode ter sobre a sensação de segurança dos estudantes. Como apontam Kosciw et al. (2012) 63,5\% dos estudantes LGBTQ (Lésbicas, Gays, Bissexuais, Transgêneros/Transexuais, Queer) pesquisados por eles afirmaram que se sentiam inseguros na escola devido à sua orientação sexual.

O participante (P.) 417 também descreveu gozações constantes:

$O$ ato de zoar foi mudando ao longo dos anos. Inicialmente porque eu usava óculos, depois sobre coisas de sexualidade que eu ainda não compreendia e, finalmente, sobre minha aparência. Primeiramente, só os meninos da minha sala me zoavam. Quando o caráter sexual entrou em jogo, meninas de outras salas também me zoavam, assim como os meninos de outras salas (os meninos da minha sala pararam, depois que briguei com um deles). Por conta disso, as meninas da minha sala não se aproximavam de mim, para não ficarem mal faladas, creio. Da $5^{a}$ para a $6^{a}$ eu decidi mudar de escola, já que não tinha amizades verdadeiras. Entretanto, por usar óculos e aparelho, começavam, nesta nova escola, a me zoarem dessa aparência, coisa que perdurou até $8^{a}$ $-1^{\circ}$ colegial. (P.417) 
Esse relato está de acordo com os dizeres de Espelage et al. (2012) de que é provável que o bullying tradicional que começa nos primeiros anos escolares motivado por variáveis como aparência física ou vestuário se transforme em perseguição baseada no gênero ou motivada por homofobia, quando a puberdade ocorre. Tal fato é preocupante, considerando que um mesmo indivíduo pode passar a vida escolar toda sofrendo vitimização por parte dos pares.

Nesse sentido, os estudantes indicaram no questionário a duração que a pior experiência escolar teve: dois afirmaram que a experiência durou "dias", dois apontaram "meses", dois "um ano", 14 relataram que a experiência durou "anos" e um afirmou "não se lembrar". Quando durou anos, foram descritos de dois a oito anos de duração; sendo que um dos participantes afirmou que essa experiência "continua acontecendo até hoje". Rivers (2004) também apontou em sua pesquisa com adultos gays que a duração média da vitimização que enfrentaram na vida escolar foi de cinco anos, mostrando que essas situações de homofobia podem se tornar estressores constantes na vida dos jovens.

No que se refere à idade que tinham na época da pior experiência escolar, a média foi de 11,4 anos, idade semelhante à descrita no estudo de Rivers (2004), de 10,5 anos. Houve variação entre sete a 17 anos, idade apontada pelo participante 356 ao descrever o isolamento social sofrido por parte dos ex-amigos:

Aos 17 anos, me assumi homossexual e decidi que os meus amigos da escola saberiam. Os meus melhores amigos (que eram dois) acharam um absurdo e, desde então, mal falo com eles. Nos limitamos ao "Oi"! $O$ mais interessante é que todos os outros alunos me aceitaram tranquilamente. (P.356)

Um participante não especificou a idade tendo descrito "adolescência". Quanto à série escolar, 16 estudantes apontaram que estavam em séries do Ensino Fundamental e quatro no Ensino Médio; um deles afirmou que ocorreu nos dois períodos. Nesse sentido, pesquisadores apontam que a época mais frequente para o bullying homofóbico é o Ensino Fundamental, possivelmente porque tais estudantes têm menos recursos emocionais e suporte para lidar com essas agressões (Kosciw et al., 2012). Por fim, 11 participantes relataram que estudavam em escolas particulares e 10 em públicas, indicando que provavelmente esse tipo de vitimização homofóbica está presente em escolas com características socioeconômicas distintas.

O questionário não permitiu a identificação dos indivíduos no que se refere à orientação sexual, no entanto, como apontam Espelage et al. (2012) a homofobia é definida como atitudes e comportamentos negativos contra indivíduos que se identificam como ou são percebidos como gays, lésbicas, bissexuais ou transgêneros. Considerando ainda o fato de que a própria adolescência é um período de desenvolvimento da identidade e questionamento da própria sexualidade (Williams et al., 2003), muitos jovens podem ser vitimizados por motivação homofóbica. Nesse sentido, foram citados relatos de rumores espalhados:

Um aluno da mesma turma inventou uma história de que eu parecia com um personagem da TV que era homossexual. Este fato fez com que eu me sentisse bastante incomodado, pois atrapalhou a minha amizade com outros alunos da turma. (P.35)

E isolamento social:

Um colega de turma com o qual eu tinha grande amizade, passou primeiramente a me destratar e ignorar por influência de amigos dele que não gostavam de mim e achar que eu era homossexual. Começou primeiramente com provocações fisicas e morais fortes, passando então a me ignorar completamente. (P.427)

Tais relatos demonstram como estudantes pertencentes a minorias sexuais ou vistos dessa forma pelos colegas podem ter dificuldade de se integrarem nos grupos de pares devido à hostilidade que enfrentam (Williams et al., 2003).

É importante pontuar que a orientação sexual se refere à atração afetiva e sexual da pessoa por outra pessoa, incluindo fantasias, comportamentos e necessidades emocionais e afetivas. A identidade de gênero é um termo mais amplo 
e está relacionada à forma como a pessoa se identifica e o como sente o seu gênero; referese, portanto, a como a pessoa se percebe, se expressa e se apresenta como homem ou mulher (Finnegan \& McNally, 2002). Tais aspectos podem ser observados nos relatos seguintes, que deixam transparecer a pressão sofrida pelos estudantes acerca das expectativas de gênero e papéis sociais a serem cumpridos, aspecto observado desde a vestimenta utilizada pelo estudante: "Aconteceu porque eu estava com um casaco com tom entre laranja e rosa, e, por ser garoto, acabei sendo zoado e chamado de 'rosinha e rosão" (P.259) e "Me lembro de ter ido com uma camiseta larga, e alguns meninos deram risada, e disseram que eu me parecia com um menino" (P.676); até mesmo rigidez sobre comportamentos esperados para o gênero:

Como eu era uma das poucas meninas que jogavam [sic] futebol, também isso era motivo para brincadeiras de mal-gosto. Não me sentia bem e achava que algo estava errado comigo. Passei a me adequar a algumas "regras sociais" após não conseguir fazer muitos amigos por conta dessas características. (P.432)

Como demonstra Russel (2011), a escola possui normas rígidas de gênero e sexualidade, tais como expectativas a respeito da masculinidade, feminilidade e heterossexualidade. Nesse sentido foram citadas também expectativas sobre como expressar a sexualidade: "Eu não quis 'ficar' com um garoto que uma amiga minha gostava e ela parou de falar comigo. Depois disso ela passou a espalhar pela escola que eu era lésbica" (P.200); " "Na sexta série, alguns meninos de minha turma começaram a fazer comentários maldosos a respeito de mim e uma amiga, pois eu não me interessava pelos meninos que se interessavam por mim, e começaram a me chamar de "sapatão"' (P.59).

Os relatos seguintes mostram a omissão de professores em situações de discriminação homofóbica:

Basicamente, duas colegas de classe especificas sempre me chamavam de "gay", influenciando os outros a chamarem tam- bém. O tom delas era muito acusatório e discriminador. Como eu não lidava bem com a minha sexualidade, ficava calado, aborrecido, envergonhado. A maioria dos professores fingia que não via o que se passava. (P.466)

$\mathrm{Ou}$, ainda, como apontam os próximos relatos, o envolvimento do professor caracterizou-se por agressão verbal: "Em relação ao professor de educação física, ele, certa vez, me chamou de viadinho na frente de outros colegas e acreditando que eu não estava ouvindo pelo fato de eu não gostar de futebol" (P.179) e,

Uma vez, num ensaio de uma peça teatral, na sétima série (eu com treze anos); errei uma marcação no palco e a professora me chamou de BAMBI na frente de todos os alunos. Os estudantes, principalmente as meninas, sempre me chamavam de gay, bicha, etc. (P.466)

Esses relatos demonstram a insegurança que os alunos podem ter na escola, não podendo contar com os professores para auxiliá-los em situações de vitimização homofóbica, fato já apontado por Kosciw et al. (2012) e Rivers (2001), de que os professores frequentemente não reportam tais situações de vitimização. Adicionalmente é disposto na literatura que os próprios professores podem vitimizar os estudantes por motivação homofóbica (Birkett et al., 2009; Kosciw et al., 2012; Venturi \& Bokany, 2011).

No que se refere à autoria da pior experiência escolar, na presente pesquisa, 19 participantes apontaram a que a autoria da pior experiência foi de outros estudantes, um relatou a autoria de professor e um o envolvimento de estudantes e de professor. Quanto ao sexo dos autores da experiência, a maioria (18), apontou que o autor era do sexo masculino, apenas dois apontaram que eram estudantes do sexo feminino e um não especificou. Os dois professores citados como autores da pior experiência eram do sexo masculino. Apesar dos dados numericamente não serem suficientes para estabelecer conclusões, os mesmos estão de acordo com a literatura no que se refere ao fato de a maioria dos alunos vitimizados por homofobia ser do sexo masculino 
(Rivers, 2001; Warner et al., 2004). Na presente pesquisa 14 eram do sexo masculino e sete do feminino; e a mesma predominância do sexo masculino ocorreu com os autores da violência homofóbica, aspecto amplamente descrito em diversos estudos (Berlan et al., 2010; DeSouza \& Ribeiro, 2005; Espelage et al., 2012; Poteat \& Espelage, 2005). Segundo dados do INEP (2010) os respondentes do sexo masculino apresentaram atitudes mais preconceituosas do que as do sexo feminino em relação a não aceitação da homossexualidade e a percepção de que os homossexuais não devem fazer parte do ambiente escolar, predominantemente formado por heterossexuais; além disso, eles procuram manter menor proximidade social com os homossexuais. Na pesquisa do INEP (2010) foi observado ainda que os alunos do sexo masculino tinham, em média, um aumento de $10,7 \%$ no índice de distância social (que indica comportamento discriminatório e predisposição para manter contato com indivíduos com características específicas) em relação a homossexuais quando comparadas às do sexo feminino.

\section{Consequências da Vitimização Escolar Homofóbica}

Conforme aponta a literatura, as experiências de vitimização homofóbica podem favorecer a ocorrência de diversos sintomas psicológicos ou psiquiátricos. Sobre o grau de incômodo que os estudantes tiveram após a experiência, 19 participantes apontaram que "incomodaram-se muito com a experiência", dois que "incomodaram-se um pouco" e nenhum assinalou a opção "não me incomodou".

Sobre os efeitos da pior experiência escolar, aspecto aferido pela parte II do instrumento ExpT, a Tabela 1 apresenta os sintomas clinicamente significativos desenvolvidos pelos participantes após a pior experiência escolar com características homofóbicas.

Tabela 1

Sintomas Desenvolvidos Após a Pior Experiência Escolar Homofóbica $(n=21)$

\begin{tabular}{|c|c|c|}
\hline Sintomas & $\begin{array}{l}N(\text { escores } \\
\text { clinicamente } \\
\text { significativos })\end{array}$ & Exemplos de itens \\
\hline Hipervigilância & 13 & "Ficava alerta para não me magoarem ou ferirem novamente" \\
\hline Evitação e entorpecimento & 8 & "Parecia não me importar com o que tinha acontecido comigo" \\
\hline Depressão & 6 & $\begin{array}{l}\text { "Sentia-me um fracasso" } \\
\text { "Era mais dificil ter iniciativa para fazer as coisas" }\end{array}$ \\
\hline Desesperança & 6 & $\begin{array}{l}\text { "Não me importava com o futuro" } \\
\text { "Sentia que a vida não valia a pena" }\end{array}$ \\
\hline Reexperienciação do trauma & 5 & "Imagens do que havia acontecido apareciam em minha mente" \\
\hline Dissociação & 5 & "Eu fantasiava por longos periodos de tempo" \\
\hline Excitabilidade aumentada & 4 & "Tinha dificuldade de me concentrar numa tarefa" \\
\hline Somatização & 4 & $\begin{array}{l}\text { "Tinha dificuldades para adormecer e ou me manter dormindo" } \\
\text { "Tinha dores de cabeça com mais frequência do que antes" } \\
\text { "Perdi meu apetite" }\end{array}$ \\
\hline Desajustamento geral & 4 & $\begin{array}{l}\text { "Desejava voltar a ser uma criancinha" } \\
\text { "Tinha medo do escuro" }\end{array}$ \\
\hline Comportamento opositivo & 3 & "Fazia o que eu queria, mesmo que as pessoas não gostassem" \\
\hline
\end{tabular}


Além dos sintomas descritos na Tabela 1, constatou-se que seis participantes atingiram escores clinicamente significativos para TEPT, resultado já apontado como posterior à homofobia na escola por Rivers (2004). Outros sintomas também foram condizentes com os descritos na literatura, principalmente no que se refere a sintomas depressivos (Birkett et al., 2009; Kosciw et al., 2012; Russell, 2011; Russell et al., 2011; Taylor et al., 2011).

A despeito do instrumento utilizado não solicitar uma descrição de como o participante se sentiu após a pior experiência escolar, alguns participantes citaram espontaneamente reações de raiva:

$\mathrm{Na}$ verdade o que acontecia eram zoações como apelidos e piadas (que para mim não eram nada engraçadas) que outros colegas faziam comigo. O periodo de 3 anos que marquei no questionário foi apenas para ressaltar o periodo em que isso me incomodava bastante. Não foi algo que me fez pensar em desistir mas foi algo que me fez ter muita raiva dessas pessoas. (P.179)

Houve reações de agressividade da parte dos participantes como forma de retaliação: "Alguns alunos me chamavam de 'frutinha' [homossexual], além de baleia [gordo], questionando a minha sexualidade. Esse 'xingamento' quando eu era criança me deixava muito mal e por isso eu corria e batia nos colegas que faziam isso comigo" (P.290), comportamento descrito na literatura como sendo frequente após a ocorrência de bullying homofóbico (Faulkner \& Cranston, 1998; Rivers, 2004). Pode-se notar pelos relatos, também, problemas com a autoestima (Kosciw et al., 2012).

O próximo relato aponta problemas com aceitação social e sensação de não pertencimento à escola, identificados também na pesquisa de Taylor et al. (2011): "Comentários irônicos, preconceituosos e maldosos acerca da minha sexualidade. Por não entender certas coisas na época me sentia mal, pois achava que tudo que desviasse da norma sexual heterossexual era 'errado' [norma]. Hoje tenho plena convicção do contrário!" (P.445).
Foram descritos ainda problemas com autoconfiança:

Sempre na escola por ser gay (não assumido) as pessoas falavam sobre minha sexualidade. As pessoas comentavam sobre mim pelas costas e às vezes acabava chegando aos meus ouvidos. Durante a sexta série me apelidaram de "Saci-gay", por ser negro e gay ... Como disse acima o fato de ter sofrido isso me tornou uma pessoa tímida e sem confiança. Hoje me apego mais facilmente com meninas. (P.487)

Tais relatos mostram os efeitos da vitimização homofóbica na dificuldade do indivíduo em estabelecer e manter relacionamentos (Rivers, 2004). Esse relato é um exemplo claro de o quanto algumas características consideradas minoritárias, como a homossexualidade e a etnia negra, podem embasar comportamentos preconceituosos por parte dos alunos. Na pesquisa do INEP (2010), por exemplo, constatou-se que os motivos mais frequentes para o bullying escolar eram o fato de o estudante ser negro (vitimização apontada por $20 \%$ ), seguido pelo fato de ser homossexual (vitimização indicada por quase $20 \%$ dos participantes).

O relato seguinte demonstra que a vitimização homofóbica pode se perpetuar ao longo da vida:

No final do terceiro colegial eu havia terminado com meu namorado de mais de um ano e me envolvi com uma menina. Ela, já assumida para os pais e para o colégio, eu como primeira experiência. Como ocorre ainda hoje, um casal lésbico gera polêmica, comentários desagradáveis, olhadas indiscretas, etc. Os comentários faziam eu me sentir mal comigo mesma, com vergonha de ser quem eu era. Como me formei alguns meses depois, o problema acabou sumindo, mas persiste na sociedade e no meu dia-a-dia. (P.114)

Nesse sentido, Rivers (2001) apontou que $55 \%$ dos participantes de sua pesquisa indicaram experienciarem vitimização ou assédio no ambiente de trabalho ou na universidade devido a sua orientação sexual; o que, para Toomey et 
al. (2010), pode afetar a vida adulta desses jovens na sua qualidade de vida como um todo. Vários autores apontam a ideação suicida como consequência após a vitimização homofóbica (Birkett et al., 2009; Bontempo \& D'Augelli, 2002; Faulkner \& Cranston, 1998; Hershberger \& D’Augelli, 1995; Rivers, 2001, 2004; Russell, 2011; Russell et al., 2011), o que pode ser observado no relato seguinte:

Eu usava a discriminação como estímulo para me esforçar e me destacar nas atividades escolares, embora, concomitantemente, pensava em me suicidar pra me livrar de tudo. Usei a solidão e o isolamento para estudar mais e tentar impressionar os professores e os alunos e provar que era inteligente. Isso me fez aprimorar as reflexões sobre a existência e daí surgiu a ideia de suicídio como fim do sofrimento. Essa época de pessimismo durou por volta de seis meses, na oitava série. (P.466)

Diferentemente dos dados descritos na literatura que apontam o desempenho escolar empobrecido (Kosciw et al., 2012; Prado \& Junqueira, 2011; Taylor et al., 2011) como consequência da homofobia na escola, nesse relato o participante descreve uma motivação maior para os estudos.

\section{Considerações Finais}

Os relatos dos estudantes sobre a vitimização envolvendo preconceito homofóbico estão de acordo com os dados da literatura, no que se refere à frequência, duração das experiências e tipos de violências; o mesmo ocorrendo com as descrições acerca do envolvimento de professores, e, principalmente, de outros estudantes como autores das piores experiências escolares homofóbicas. Além disso, os principais sintomas descritos pelos participantes, após tais experiências de homofobia, preocupam ao apontar sérios impactos sobre o bem estar e saúde mental dos jovens, como risco de depressão e suicídio.

Sabe-se que os anos escolares no Ensino Fundamental tem um forte impacto no desenvolvimento acadêmico e social dos adolescentes. Pesquisas, tais como Kosciw et al. (2012) e Taylor et al. (2011), mostram que estudantes
LGBT que percebem a escola como um ambiente seguro apresentam índices mais baixos para problemas psicossociais, mostrando que um clima escolar positivo pode proteger os estudantes da vitimização homofóbica, prevenindo efeitos maléficos para a saúde mental. Dessa forma, as escolas devem implementar políticas anti-homofobia, promovendo orientações para estudantes, pais, e equipe nesse compromisso de fazer a escola segura (Taylor et al., 2011; Toomey et al., 2010; Williams et al., 2003), promovendo climas escolares positivos e reduzindo o bullying homofóbico (Birkett et al., 2009). Parte das estratégias de enfrentamento diante do bullying homofóbico envolve o oferecimento de cursos de capacitação para profissionais lidarem com a questão na escola (Taylor et al., 2011), evitando o uso de segregações de gênero como uniformes escolares, danças e atividades extracurriculares que limitem a expressão dos jovens, por exemplo (Toomey et al., 2010).

Para Russell (2011) um corpo crescente de trabalhos indica que as seguintes estratégias de intervenção estão associadas a climas escolares mais seguros para estudantes LGBT: regulamento detalhado de não discriminação e antibullying; intervenção dos professores quando o assédio ocorre; disponibilidade de informação e apoio sobre questões LGBT para os estudantes; presença de grupos de apoio ou clubes com base na escola (frequentemente denominados "alianças gay-hetero"); e inclusão curricular de questões LGBT (Russell, 2011). Essas inclusões curriculares são consideradas benéficas porque preparam os estudantes para a sociedade democrática, debatendo temas importantes (Russell, 2011). Nesse sentido, Venturi e Bokany (2011) apontam que as taxas de homofobia tendem a cair na medida em que as pessoas têm contato com indivíduos LGBT.

Prado e Junqueira (2011) relembram que somente na década de 80 a homossexualidade foi retirada do Manual de Diagnóstico e Estatístico dos Transtornos Mentais (DSM), não sendo mais uma categoria diagnóstica e no Brasil apenas no ano de 1999 o Conselho Federal de Psicologia aprovou a resolução que proíbe intervenções psicológicas que objetivem a "cura" 
da homossexualidade. As pesquisas na área da homofobia aumentaram após a revisão do DSM na qual a homossexualidade foi removida como uma categoria diagnóstica (Wright, Adams, \& Bemat, 1999), mas ainda há muito que ser estudado, especialmente no Brasil onde as pesquisas desse tipo são escassas (DeSouza \& Ribeiro, 2005). Segundo Venturi e Bokany (2011) existe muito a ser feito no debate público da tolerância à diferença e na elaboração de políticas públicas, como, por exemplo, aprimoramento da legislação para punir casos de homofobia (Venturi \& Bokany, 2011) e orientação aos agressores.

Resumindo, medidas sociais amplas e especificamente no ambiente escolar poderão favorecer situações futuras em que os estudantes tenham a mesma oportunidade de aprender no ambiente escolar independentemente de sua orientação sexual ou identidade de gênero (Kosciw et al., 2012). Espera-se que esse trabalho contribua para esclarecimento da seriedade dos efeitos da homofobia na escola, contribuindo também para o delineamento de intervenções que combatam esse tipo de violência.

\section{Referências}

Albuquerque, P.P. \& Williams, L.C.A. (2014). Evidências de validade da escala "Student Alienation and Trauma Survey - R". Avaliação Psicológica, 13(1), 115-124.

Bekaert, S. (2010). Tackling homophobic attitudes and bullying in youth settings. Pediatric Nursing, 22(3), 27-29. doi:10.7748/paed2010.04.22.3.27. c7639

Berlan, E. D., Corliss, H. L., Field, A. E., Goodman, E., \& Austin, S. B. (2010). Sexual orientation and bullying among adolescents in the growing up today study. Journal of Adolescent Health, 46, 366-371. doi:10.1016/j.jadohealth.2009.10.015

Birkett, M., Espelage, D. L., \& Koenig, B. (2009). LGB and questioning students in schools: The moderating effects of homophobic bullying and school climate on negative outcomes. Journal of Youth and Adolescence, 38, 989-1000. doi:10.1007/s10964-008-9389-1

Bontempo, D. E., \& D’Augelli, A. R. (2002). Effects of at-school victimization and sexual orientation on lesbian, gay, or bisexual youths' health risk behavior. Journal of Adolescent Health, 30, 364-374. doi:10.1016/S1054-139X(01)00415-3

Borrillo, D. (2009). A homofobia. In T. Lionço \& D. Diniz (Eds.), Homofobia \& Educação: Um desafio ao silêncio (pp. 15-46). Brasilia, DF: Letras Livres.

DeSouza, E. R., \& Ribeiro, J. (2005). Bullying and sexual harassment among Brazilian high school students.JournalofInterpersonal Violence, 20(9), 1018-1038. doi:10.1177/0886260505277731

Espelage, D. L., Basile, K. C., \& Hamburger, M. E. (2012). Bullying perpetration and subsequent sexual violence perpetration among middle school students. Journal of Adolescent Health, 50, 60-65. doi:10.1016/j.jadohealth.2011.07.015

Faulkner, A. H., \& Cranston, K. (1998). Correlates of same-sex sexual behavior in a random sample of Massachusetts high school students. American Journal of Public Health, 88(2), 262-266. doi:10.2105/AJPH.88.2.262

Finnegan, D. G., \& McNally, E. B. (2002). Counseling lesbian, gay, bisexual and transgender substance abusers: Dual identities. Binghamton, NY: The Haworth Press.

Hershberger, S. L., \& D’Augelli, A. R. (1995). The impact of victimization on the mental health and suicidality of lesbian, gay, and bisexual youths. Developmental Psychology, 31(1), 6574. doi:10.1037/0012-1649.31.1.65

Hyman, I., \& Snook, P. A. (2002). Manual for the My Worst Experience Scales (MWES). Los Angeles, CA: Western Psychological Services.

Instituto Nacional de Estudos e Pesquisas Educacionais Anísio Teixeira. (2010). Pesquisa Nacional diversidade na escola. Recuperado em portal. mec.gov.br/dmdocuments/sumario_diversidade. pdf

Kosciw, J. G., Greytak, E. A., Bartkiewicz, M. J., Boesen, M. J., \& Palmer, N. A. (2012). The 2011 National School Climate Survey: The experiences of lesbian, gay, bisexual and transgender youth in our nation's schools. New York: Gay, Lesbian \& Straight Education Network.

Olweus, D. (1991). Bully/victim problems among school children: Basic facts and effects of a school based intervention program. In D. Pepler \& K. Rubin (Eds.), The development and treatment of childhood aggression (pp. 411-448). Hillsdale, NJ: Erlbaum. 
Poteat, V. P., \& Espelage, D. L. (2005). Exploring the relation between bullying and homophobic verbal content: The Homophobic Content Agent Target (HCAT) Scale. Violence and Victims, 20(5), 513-528. doi:10.1891/vivi.2005.20.5.513

Prado, M. A. M., \& Junqueira, R. D. (2011). Homofobia, hierarquização e humilhação social. In G. Venturi \& V. Bokany (Eds.), Diversidade sexual e homofobia no Brasil (pp. 51-71). São Paulo, SP: Editora da Fundação Perseu Abramo.

Rivers, I. (2001). The bullying of sexual minorities at school: Its nature and long-term correlates. Educational and Child Psychology, 18(1), 32-46.

Rivers, I. (2004). Recollections of bullying at school and their long-term implications for lesbians, gay men, and bisexuals. Crisis, 25(4), 169-175. doi:10.1027/0227-5910.25.4.169

Russell, S. T. (2011). Challenging homophobia in schools: Policies and programs for safe school climates. Educar em Revista, 39, 123-138. doi:10.1590/S0104-40602011000100009

Russell, S. T., Ryan, C., Toomey, R. B., Diaz, R. M., \& Sanchez, J. (2011). Lesbian, gay, bisexual and transgender adolescent school victimization: Implications for young adult health and adjustment. Journal of School Health, 81(5), 223-230. doi:10.1111/j.1746-1561.2011.00583.x

Taylor, C., Peter, T., \& Paquin, S. (2011). "School is not a safe place for anyone like me": The first National Climate Survey on Homophobia in Canadian Schools. In D. Pepler, J. Cummings, \& W. Craig (Eds.), Creating a world without bullying: Vol. 3. PREVNet Series. Otawa, Canada: Canada National Printers.

Toomey, R. B., Ryan, C., Diaz, R. M., Card, N. A., \& Russel, S. T. (2010). Gender-nonconforming lesbian, gay, bisexual, and transgender youth: School victimization and young adult psychosocial adjustment. Developmental Psychology, 46(6), 1580-1589. doi:10.1037/a0020705
Venturi, G., \& Bokany, V. (2011). Foco na homofobia: A coleta e a análise dos dados. In G. Venturi \& V. Bokany (Eds.), Diversidade sexual e homofobia no Brasil (pp. 51-71). São Paulo, SP: Editora da Fundação Perseu Abramo.

Warner, J., Mckeown, E., Griffin, M., Markgriffin, S., Johnson, K., Ramsay, A., ...King, M. (2004). Rates and predictors of mental illness in gaymen, lesbians and bisexualmen and women: Results from a survey based in England and Wales. British Journal of Psychiatry, 185, 479-485. doi:10.1192/bjp.185.6.479

Williams, T., Connolly, J., Pepler, D., \& Craig, W. (2003). Questioning and sexual minority adolescents: High school experiences of bullying, sexual harassment and physical abuse [Special issue]. Canadian Journal of Community Mental Health, 22(2), 47-58. doi:10.7870/ cjcmh-2003-0013

Wright, L. W., Adams, H. E., \& Bemat, J. (1999). Development and validation of the Homophobia Scale. Journal of Psychopathology and Behavioral Assessment, 21(4), 337-347. doi:10.1023/A:1022172816258
Recebido: 05/03/2014 Aceite final: 08/08/2014 